\section{The Imperial Tongue: English as the Dominating Academic Language}

\section{Philip G. Altbach}

Philip G. Altbach is Monan professor of higher education and director of the Center for International Higher Education at Boston College.

$\mathrm{T}$ he English language dominates science, scholarship, and instruction as never before. While it is unlikely that English will achieve the status that Latin had as the sole language of teaching and scholarship at the I3th-century universities in Europe, the Latin analogy has some relevance today. Back then, Latin not only permitted the internationalization of universities but allowed the Roman Catholic Church to dominate intellectual and academic life. It was only the Protestant Reformation led by Martin Luther, combined with a growing sense of national identity, that challenged and then displaced Latin with national languages. As late as the I930s, German was a widely used international scientific language. Until the mid-2oth century, most countries used their national languages for university teaching and for science and scholarship. French, German, Russian, and Spanish were, and to some extent still are, used for academic and scientific publications and have some regional sway. Scholarly communities in Japanese, Chinese, Swedish, and many other languages continue to exist as well. English was the closest thing to an international language, with several major academic systems using it-the United States, Britain, Australia, New Zealand, and most of Canada. In addition, the emerging academic systems of the former British Empire-especially India, Pakistan, South Africa, and Nigeria-have traditionally used English as the main teaching and publishing language. But English did not dominate scholarly communication until the I950s, and national academic communities seemed in general committed to national languages.

English now serves unchallenged as the main international academic language. Indeed, national academic systems enthusiastically welcome English as a contributor to internationalizing, competing, and becoming "world class." But the domination by English moves world science toward hegemony led by the main English-speaking academic systems and creates difficulties for scholars and universities that do not use English.

\section{Origins Of English Hegemony}

It is not hard to see why English is the dominant academic and scientific language. The nations using English, particularly the United States, have become the academic superpowers. Size and wealth matter a great deal in determining the academic pecking order. The United States alone spends almost half the world's R\&D funds and is home to a large proportion of the top universities on the world's increasingly influential league tables. The English-speaking academic systems host more than half the world's international students. Many of these graduates return to their home countries with a zeal for English and for the foreign universities at which they obtained their degrees. The main scientific and scholarly journals are published in English because their editors and most of their contributors are professors at universities in the Englishspeaking countries. Similarly, the large majority of the world's academic Web sites and scientific networks function in English.

English is the world's most widely studied second language. This gives English a significant advantage in many nonEnglish-speaking countries simply because of the number of speakers and the fact that English is by far the most widely distributed language. There are, for example, more students studying English in China than are studying English in the United States and more speakers of English in India than in Britain. Further, English has an official governmentally recognized status in more than 70 countries. Colonialism provided stimulus for the spread of English (as well as other European languages) as early as the I8th century-to North America, South Asia, and the Caribbean - and later to Africa, other parts of Asia, Australasia, and the South Pacific. Today, no African university offers instruction in any indigenous African language, and academic and intellectual life takes place in English, French, Portuguese, Arabic, and Afrikaans.

Until the mid-2oth century, most countries used their national languages for university teaching and for science and scholarship.

\section{Evidence of English Hegemony}

The international role of English and its growing role in academic life worldwide have many implications. The power of English-language scientific and scholarly journals means that the research paradigms and scholarly interests of the journal editors, editorial board members, and indeed the majority of readers control journals and to a large extent research agendas and methodologies in most disciplines. Scholars in other parts of the world must conform to the interests of the prestigious journals if they wish their work to be published in them. While the Internet is more open, the interests of the major contributors and users tend to dominate, and the English language is most widely used. International scientific meetings increasingly use English as the only official language.

The curriculum is increasingly dominated by the major English-speaking countries, and in a globalized world this 
means that curricular developments are expressed in English and increasingly come from the United States and a few other countries. The international proliferation of the master of business administration degree (MBA) is a good example of how academic programs spread. The MBA degree was developed in the United States to serve the needs of American business and became the standard qualification required by senior executives. In the past two decades, English has become recognized as a key qualification for management in other countries, compelled both by the growing influence of multinational corporations and by the power of American universities. US universities now offer MBA degrees in many parts of the world, and

\section{The impact of English in most cases increases the} influence of the major English-speaking academic systems.

non-US universities have established their own MBA programs, often using English and a largely US curriculum. This development shows the power both of the English language and of American higher education practices and ideas.

The academic journals and books published in English and edited from the United States and the United Kingdom increasingly dominate world scholarship. These publications are almost the only ones internationally circulated. They are the most prestigious journals, and academics worldwide compete to publish in them. They are listed in the Science Citation Index and its sister indexes. While SCI was not developed to rank journals or to measure the scholarly productivity of individual academics or institutions but rather to trace how scientific ideas become influential and are communicated, it has become a de facto ranking. Universities worldwide want their professors to publish in these listed journals and reward those who do. For example, Norwegian academics who publish in English and in recognized journals are paid fees for their accomplishments, while their colleagues who publish in Norwegian are paid less or not at all. In Korea, great pressures are placed on academics to publish in recognized international journals in English. Publication in English and in internationally recognized journals and by prestigious international publishers counts more than publishing elsewhere.

Academic programs offered in English have become widespread in many non-English-speaking countries. Universities in Europe, Asia, and Latin America are offering degree programs in English alongside instruction in national languages. A small number of new private universities operating solely in English have also been established, sometimes calling themselves the American University of . . to take advantage of the prestige and popularity of English. In some cases, these universities seek accreditation in the United States, and for a few such institutions accreditation has been granted.

The worldwide branch campus movement for the most part uses English as the medium of instruction. The United States, Australia, and the United Kingdom have been most active in establishing branch campuses, and it is not surprising that English is the medium of instruction. Non-English-speaking countries often use English as well. Dutch and German branch overseas campuses often offer their programs in English. There are at least Ioo branch campuses, mainly sponsored by universities in the North and operating in the South. The branch campus movement exports both language and curriculum, introducing new ideas into host countries and perhaps displacing national models.

Most observers see the impact of English in higher education worldwide as a positive trend-contributing to globalization and enhancing an international academic culture. A global academic environment needs a common medium of communication, and English is the only possible language. While English brings new ideas to sometimes moribund academic institutions worldwide, there are significant downsides to the new hegemony of English.

\section{DOWNSIDES}

The impact of English increases the influence of the major English-speaking academic systems, particularly of the United States and the United Kingdom. These countries have many of the world's leading universities, produce a high proportion of scientific discoveries and scholarship, and form the centers of scientific communication. The norms, values, methodologies, and orientations of the academic communities of these centers tend to dominate the rest of the world-the peripheries.

What happens to national scientific communities in an English-dominated global environment? There has always been a tension between the local and the global in science and

Academic rewards of all kinds accrue to those using English and participating in global scientific networks.

scholarship-since knowledge is by its nature international. The use of national languages and the existence of national journals and publishers are called into question by policymakers and academic administrators worldwide. Knowledge is ranked according to whether it is recognized by the international academic community or not. If not, even though a domestic publication may be highly relevant to national needs, it is considered even within a country as being less prestigious, and this may have implications for a scholar's academic career or salary. Ambitious academics will naturally seek to publish in international publications to advance their impact and careers. Topics such as local history or research on local health problems may be ignored to gain recognition internationally.

Some time ago, the Dutch minister of education proposed that universities in the Netherlands shift the language of 
instruction from Dutch to English so that Holland could boost its attraction for international students and integrate more fully into the global scholarly community. The Dutch Parliament debated the issue and decided not to shift the language-arguing that the Netherlands would lose its distinctive culture if the Dutch language was no longer used for intellectual and academic life. This argument is relevant elsewhere. If the knowledge that is most valued is aimed at the international academic world and is communicated in English, there will be negative implications for national scientific and intellectual systems.

In many countries, academic rewards of all kinds accrue to those using English and participating in global scientific networks. These scholars are typically invited to international conferences, awarded research funds by both international and national funders, and are generally seen as leaders of their scientific communities. Universities and governments often use the SCI and related systems to judge the impact and value of their academics and universities. SCI becomes a kind of proxy for quality and productivity. Similarly, the international ranking systems use such measures. However, again, this offers privileges those who produce their work in English and intend to reach an international audience.

These factors will tend to orient researchers and scholars to themes that they feel will appeal to an international audience, often at the expense of essential but more parochial themes that might be of interest only to local or national audiences. Further, the methodologies chosen for research will follow those popular internationally, whether these methods are relevant to the specific topic being researched.

The current debate concerning the General Agreement on Trade in Services (GATS) as part of the World Trade Organization (WTO) has direct implications for this discussion. GATS will force academic systems worldwide to be more open to foreign influences. Should GATS be widely implemented, this will inevitably mean the English-language institutions and programs will further entrench themselves worldwide.

These factors lead to homogenizing knowledge worldwide. Not only is English the dominant language, but its relationship with the controlling trends in international science and scholarship is a powerful combination of forces contributing to decreasing diversity of themes and methodologies.

\section{What Can Be Done?}

If globalization determines the direction of the world economy, science, and other factors, then the growth of English as the global language of science and scholarship is inevitable for the foreseeable future. Science indeed is increasingly international, and the global mobility of students and professors is a longterm reality. There is an international knowledge network that involves not only science and scholarship but increasingly people. This network operates mainly in English and is dominated by the main English-speaking academic systems.
The argument here is that the international network is both inevitable and largely positive but that national and local scientific communities and higher education systems must be protected. These communities deserve both respect and support because they bring a valuable perspective and diversity to science and scholarship. Internationalization may be positive but with homogenization we lose a concern for local and regional issues as well as ideas that may not be in the international mainstream. An entirely open market will weaken these communities, just as the major world languages today are snuffing out small and weak languages. Science and scholarship in national languages deserve support. The evaluation of academic merit should not depend solely on the rankings of the SCI or other exogenous agencies-and thus left to the judgment of foreigners. While local evaluation may not be easy, it is necessary. An appropriate mix between local and international publication will help nurture an active research community.

The essential necessity is an understanding of the importance of national scientific and intellectual communities. Creating a balance between the local and the global may not be easy but intellectual independence depends on it.

\section{The Global Higher Education Race}

\section{John Aubrey Douglass}

John Aubrey Douglass is senior research fellow at the Center for Studies in Higher Education at the University of California, Berkeley. Address: Center for Studies in Higher Education, South Hall Annex, University of California, Berkeley, CA 94720-4650, USA. E-mail: douglass@berkeley.edu.

The United States pioneered the idea of mass higher educa1 tion, reaping tremendous economic and social advantages. Now much of the world has embraced this model on its own political and cultural terms. The higher education race is driven by the idea that education will increasingly play a decisive role in national economic competitiveness and socioeconomic mobility. As a result, higher education has become a major global growth sector. Despite significant differences among nations and regions in the structure and culture of their academic enterprises, certain similarities in policy approaches and trajectories are creating, in turn, dramatic enrollment and program growth.

Yet in the midst of this global trend, America has entered a period of stagnant higher education access and graduation rates. This downturn is perhaps not fully understood through- 